\title{
The Pattern of Pregnancy Related Complications and Health-Seeking Behavior of Rural Women
}

Dr. Rumana Rashid ${ }^{1 *}$, Dr. Abdullah Abu Sayeed ${ }^{2}$, Md. Nazmul Karim ${ }^{3}$, Dr. Md. Monjurul Hakim ${ }^{4}$, Dr. Fariha Fairouz ${ }^{5}$, Md Abul Faiz ${ }^{6}$, Dr. Afroza Begum ${ }^{7}$

${ }^{1}$ Assistant Professor, Epidemiology and Community Medicine, Bangladesh Institute of Tropical and Infectious Diseases, Chittagong, Bangladesh

${ }^{2}$ Assistant Professor, Medicine, Chittagong Medical College, Chittagong, Bangladesh

${ }^{3}$ School of Public Health and Preventive Medicine, Monash University, Australia

${ }^{4}$ Assistant Professor, Dept. of Community Medicine, Rangamati Govt. Medical College, Rangamati, Bangladesh

${ }^{5}$ Intern, Ibrahim Medical College, Dhaka, Bangladesh

${ }^{6}$ Professor of Medicine (Rtd), Sir Salimullah Medical College, Dhaka, Bangladesh

${ }^{7}$ Professor and Head, Dept of Maternal and Child Health, National Institute of Preventive \& Social Medicine, Dhaka, Bangladesh

DOI: $10.36347 /$ sjams.2020.v08i05.019

| Received: 23.04.2020 | Accepted: 30.04.2020 | Published: 14.05.2020

*Corresponding author: Dr. Rumana Rashid

Abstract

Original Research Article

Objective: In this study our main goal is to evaluate the pattern of pregnancy complications and health care seeking behavior used by families in rural Bangladesh. Method: This cross-sectional prospective observational type of study was conducted among 112rural women of reproductive age group of Anwara Upazilla, who delivered or whose baby died during delivery due to pregnancy related complication within last 24 months conducted at two community clinic, two upazilla union health Centre and two family welfare centers during 6 months from January 2010 to June 2010. Results: During the study, among the respondents majority of them (82\%) were in the age group of $20-30$ years and the mean $( \pm \mathrm{SD})$ age of the respondents was 25.05 ( \pm 4.33$)$ years. Also,33 respondents $(66.7 \%)$ suffered from pregnancy complications like excessive vomiting and severe headache with blurring vision; $27.3 \%$ respondent suffered from swelling of leg or face, $18.2 \%$ respondents from anemia.52.2\%) respondents seek treatment in government hospital and rest of them in private clinic. Conclusion: From our study we can conclude that, all the respondents who developed complications during delivery and after delivery sought health care. Among the respondents who did not receive antenatal care developed more complications during pregnancy period and delivery period which is statistically. Care seeking behavior is closely related with pregnancy complication. Timely and properly seeking treatment could help to reduce maternal mortality and morbidity and ultimately helps to reach MDG Goal.

Keywords: Pregnancy complications, care seeking behavior and severe headache.

Copyright @ 2020: This is an open-access article distributed under the terms of the Creative Commons Attribution license which permits unrestricted use, distribution, and reproduction in any medium for non-commercial use (NonCommercial, or CC-BY-NC) provided the original author and source are credited.

\section{INTRODUCTION}

Pregnancy is a normal, healthy state that most women desire at some point of their lives. Yet while pregnancy and childbirth should be an occasion for rejoicing, life-threatening complications may occur, which if inappropriately managed, could lead to maternal death or disability. Most of these deaths (99\%) occur in developing countries. Every minute, one maternal death occurs somewhere in the developing world. Every year over half a million women die during pregnancy and following childbirth, 174000 of these in the South-East Asia (SEA) Region of WHO. The maternal mortality ratio (MMR) in the SEA Region in 2000 was estimated at 460 per 100000 live births. The lifetime risk of maternal death is 1 in 58 in this Region[1].
Complications of pregnancy and childbirth cause more deaths and disability than any other reproductive health problems [2]. In developing countries, many mothers experience serious health problems during pregnancy, delivery and the postnatal period that require professional care, but they often remain unaware of the serious nature of their illness. Of the 5, 29,000 maternal deaths occurring annually worldwide, $99 \%$ occur in developing countries [3].

Seeking care from a basic or comprehensive facility in response to obstetric complications is a key behavior promoted in safe motherhood programs. This study examined the pattern of pregnancy complications and care seeking behavior used by families in rural Bangladesh. 


\section{OBJECTIVE}

\section{General Objective}

- To determine the pregnancy related complications and health care seeking behavior of rural women.

\section{Specific Objectives}

- To assess the ante natal care information among the respondents.

- To determine the socio-demographic status of rural mothers.

\section{Methodology}

\begin{tabular}{|l|l|}
\hline Type of study & Cross-sectional study \\
\hline Place of study & Two community clinic, two upazilla union health Centre and two-family welfare centers \\
\hline Study period & 6 months from January 2010 to June 2010. \\
\hline Study population & $\begin{array}{l}\text { 112rural women of reproductive age group of AnwaraUpazilla, who delivered or whose } \\
\text { baby died during delivery due to pregnancy related complication within last 24 months. }\end{array}$ \\
\hline Sampling technique & Purposive \\
\hline
\end{tabular}

\section{Study procedure}

After reached at Anwaraupazilla, Upazilla Health Complex (UHC) was visited. With the help of THO at first a list of villages was taken. Then randomly selected 3 villages. From that 3 village sample were taken. Face to face interview of the participants were conducted with the semi-structured, pre-tested questionnaire. The interview was conducted anonymously and privately as much as possible. Before preceding the data collection, the detail of the study was explicitly explained to each eligible respondent and informed written consents from the respondents were obtained.

\section{Data Analysis}

Data were entered in the template of Statistical program, SPSS-15 after necessary editing and coding.
Descriptive statistics were generated for sociodemographic variables and were presented with relative frequency. For assessing the compilations and health seeking pattern relevant data were analyzed along with the descriptive statistics. Cross tabulation of the selected complication and key health seeking practice variables were done to explore the association through chi square test at a significance level of $\mathrm{P}<0.05$.

\section{RESULTS}

In table-1 shows socio-demographic variables among the respondents. Majority of them (82\%) were in the age group of $20-30$ years and the mean $( \pm$ SD) age of the respondents was $25.05( \pm 4.33)$ years. The following table is given below in detail:

Table-01: Distribution of socio-demographic variables among the respondents $(\mathbf{n}=112)$

\begin{tabular}{|l|l|l|l|}
\hline Socio-demographic Variables & Frequency & Percentage (\%) \\
\hline \multirow{4}{*}{ Age Groups } & $<20$ Years & 05 & 4.5 \\
\cline { 2 - 4 } & 20 to 30 Years & 92 & 82.1 \\
\cline { 2 - 4 } & $>30$ Years & 15 & 13.4 \\
\hline \multirow{2}{*}{ Religion } & Muslim & 72 & 64.3 \\
\cline { 2 - 4 } & Hindu & 40 & 35.7 \\
\hline \multirow{2}{*}{$\begin{array}{l}\text { Monthly } \\
\text { Family Income }\end{array}$} & $<5000 \mathrm{Tk}$ & 52 & 46.4 \\
\cline { 2 - 4 } & 5000 to $10000 \mathrm{Tk}$ & 52 & 46.4 \\
\cline { 2 - 4 } & $>10000 \mathrm{Tk}$ & 08 & 7.2 \\
\hline \multirow{3}{*}{ Family Size } & $<4$ & 05 & 4.5 \\
\cline { 2 - 4 } & 4 to 5 & 68 & 60.7 \\
\cline { 2 - 4 } & $>5$ & 39 & 34.8 \\
\hline Total & & 112 & 100.0 \\
\hline
\end{tabular}

In table-2 shows educational \& occupational status among the respondents and their husbands. Among the respondents $40.2 \%$ were illiterate and could sign only, $14.3 \%$ studied up to SSC or above. Among the husbands $50.8 \%$ were illiterate and could sign only, $10.2 \%$ studied up to SSC or above. The following table is given below in detail: 
Table-2: Distribution of educational \& occupational status among the respondents and their husbands $(\mathbf{n}=112)$

\begin{tabular}{|l|l|l|l|}
\hline \multicolumn{2}{|c|}{ Educational \& Occupational Status } & Among Respondents (\%) & $\begin{array}{l}\text { Among } \\
\text { Husbands (\%) }\end{array}$ \\
\hline Educational Status & Illiterate & 21.4 & 25.8 \\
\cline { 2 - 4 } & Can Sign Only & 18.8 & 25.0 \\
\cline { 2 - 4 } & Class I - V & 23.2 & 19.6 \\
\cline { 2 - 4 } & Class VI - X & 22.3 & 18.8 \\
\cline { 2 - 4 } & SSC Passed & 11.6 & 4.5 \\
\cline { 2 - 4 } & HSC \& Above & 2.7 & 5.7 \\
\hline Occupational Status & House Wife & 99.1 & 0.0 \\
\cline { 2 - 4 } & Day Laborer & 0.0 & 38.4 \\
\cline { 2 - 4 } & Service Holder & 0.9 & 18.8 \\
\cline { 2 - 4 } & Farmer & 0.0 & 17.2 \\
\cline { 2 - 4 } & Businessman & 0.0 & 9.8 \\
\cline { 2 - 4 } & Others & 0.0 & 100.0 \\
\hline Total & & 100.0 & \\
\hline
\end{tabular}

In table-3 shows background information of family among the respondents where in patients' family $80 \%$ patients' husbands were main earning member of the family. Also, $51.8 \%$ patients belong from nuclear Family. The following table is given below in detail:

Table -3: Distribution of background information of family among the respondents $(\mathbf{n}=112)$

\begin{tabular}{|l|l|l|l|}
\hline Background Information of Family & Frequency & Percentage (\%) \\
\hline Earning Member & Self & 01 & 0.9 \\
\cline { 2 - 4 } & Husband & 90 & 80.3 \\
\cline { 2 - 4 } & Others & 21 & 18.8 \\
\hline \multirow{3}{*}{ Type of Family } & Joint Family & 54 & 48.2 \\
\cline { 2 - 4 } & Nuclear Family & 58 & 51.8 \\
\hline \multirow{3}{*}{ Type of House } & Kacha & 97 & 86.6 \\
\cline { 2 - 4 } & Semi Pacca & 11 & 9.8 \\
\cline { 2 - 4 } & Pacca & 04 & 3.6 \\
\hline Total & & 112 & 100.0 \\
\hline
\end{tabular}

In table-4 shows distribution of decision makers in family among the respondents. Most of the cases husbands were responsible for decision in health care seeking of respondents. The following table is given below in detail:

Table-4: Distribution of decision makers in family among the respondents $(n=112)$

\begin{tabular}{|l|l|l|l|}
\hline Decision Makers in Family & Frequency & Percentage (\%) \\
\hline \multirow{2}{*}{$\begin{array}{l}\text { About } \\
\text { Family Affairs }\end{array}$} & Husband & 94 & 83.9 \\
\cline { 2 - 4 } & Parent-in-Laws & 15 & 13.4 \\
\cline { 2 - 4 } & Others & 03 & 2.7 \\
\hline \multirow{2}{*}{ About } & Husband & 97 & 86.6 \\
\cline { 2 - 4 } & Parent-in-Laws & 12 & 10.7 \\
\cline { 2 - 4 } & Others & 03 & 2.7 \\
\hline Total & & 112 & 100.0 \\
\hline
\end{tabular}

In table- 5 shows reproductive histories among the respondents. Most of the patients had 2 children, $41.1 \%$. The following table is given below in detail:

Table-5: Distribution of reproductive histories among the respondents $(n=112)$

\begin{tabular}{|l|c|l|l|}
\hline \multicolumn{2}{|l|}{ Reproductive History } & Frequency & Percentage (\%) \\
\hline No. of Pregnancy & 1 & & 28.6 \\
\cline { 2 - 4 } & 2 & & 38.4 \\
\cline { 2 - 4 } & 3 & & 17.9 \\
\cline { 2 - 4 } & 4 & & 8.0 \\
\cline { 2 - 4 } & 5 & & 7.1 \\
\hline No. of Children & 1 & & 32.1 \\
\cline { 2 - 4 } & 2 & & 41.1 \\
\cline { 2 - 4 } & 3 & & 14.3 \\
\cline { 2 - 4 } & 4 & & 10.7 \\
\cline { 2 - 4 } & 5 & & 1.8 \\
\hline Total & & 112 & 100.0 \\
\hline
\end{tabular}


In Table- 6 shows distribution of ante natal care information among the respondents. Among the respondent $63.4 \%$ received $\mathrm{ANC}$, among those who have received $\mathrm{ANC} ; 32.4 \%$ took it more than 4 times,
$43.7 \%$ received it in four occasions and around $24 \%$ received it in three or less occasions. The following table is given below in detail:

Table-6: Distribution of ante natal care information among the respondents

\begin{tabular}{|l|l|l|l|}
\hline \multicolumn{2}{|l|}{ ANC Information } & Frequency & Percentage (\%) \\
\hline \multirow{2}{*}{ ANC (n = 112) } & Received & 71 & 63.4 \\
\cline { 2 - 4 } & Not Received & 41 & 36.6 \\
\hline \multirow{2}{*}{$\begin{array}{l}\text { No. of ANC Visits } \\
\mathrm{n}=71)\end{array}$} & $<4$ Times & 17 & 23.9 \\
\cline { 2 - 4 } & 4 Times & 31 & 43.7 \\
\cline { 2 - 4 } & $>4$ Times & 23 & 32.4 \\
\hline \multirow{2}{*}{$\begin{array}{l}\text { Place of ANC } \\
(\mathrm{n}=71)\end{array}$} & FWC & 19 & 26.8 \\
\cline { 2 - 4 } & Govt. Hospital & 34 & 47.8 \\
\cline { 2 - 4 } & Private Hospital & 12 & 16.9 \\
\cline { 2 - 4 } & Satellite Clinic & 06 & 8.5 \\
\hline Reason for Not Seeking ANC $(\mathrm{n}=41)$ & No Money & 26 & 63.4 \\
\cline { 2 - 4 } & Prohibition from & 15 & 36.6 \\
& Family Members & & \\
\hline
\end{tabular}

In table-7 shows post-natal care information among the respondents. Most of the patients didn't receive any post-natal care, $74.1 \%$. The following table is given below in detail:

Table -7: Distribution of post-natal care information among the respondents

\begin{tabular}{|l|l|l|l|}
\hline \multicolumn{2}{|l|}{ PNC Information } & Frequency & Percentage (\%) \\
\hline \multirow{2}{*}{ PNC (n=112) } & Received & 29 & 25.9 \\
\cline { 2 - 4 } & Not Received & 83 & 74.1 \\
\hline $\begin{array}{l}\text { Reasons for PNC } \\
(\mathrm{n}=29)\end{array}$ & For Advice & 21 & 72.4 \\
\cline { 2 - 4 } $\begin{array}{l}\text { Place of PNC } \\
(\mathrm{n}=29)\end{array}$ & For Complication & 08 & 27.6 \\
\cline { 2 - 4 } & Govt. Hospital & 08 & 27.6 \\
\cline { 2 - 4 } & Private Clinic & 06 & 20.8 \\
\cline { 2 - 4 } & Satellite Clinic & 13 & 44.8 \\
\cline { 2 - 4 } & Pharmacy & 01 & 3.4 \\
\cline { 2 - 4 } & At Home & 01 & 3.4 \\
\hline \multirow{5}{*}{ Reason for Not Seeking PNC (n=83) } & Don't Know & 71 & 85.6 \\
\cline { 2 - 4 } & Expenditure & 09 & 10.8 \\
\cline { 2 - 4 } & Refusal of Decision Maker of Family & 02 & 2.4 \\
\cline { 2 - 3 } & Distance from & 01 & 1.2 \\
\hline
\end{tabular}

In table- 8 shows complications among the respondents where $70.5 \%$ patients had complication during pregnancy. The following table is given below in detail:

Table-8: Distribution of complications among the respondents $(n=112)$

\begin{tabular}{|l|l|l|l|}
\hline & \multicolumn{3}{|l|}{ Complications } \\
\cline { 2 - 4 } & During Pregnancy & During Delivery & Post-Delivery \\
\hline Present & $33(29.5)$ & $15(13.4)$ & $14(12.5)$ \\
\hline Absent & $79(70.5)$ & $97(86.6)$ & $98(87.5)$ \\
\hline
\end{tabular}

In table-9 shows types of complications among the respondents. Among 33 respondents (66.7\%) suffered from pregnancy complications like excessive vomiting and severe headache with blurring vision; $27.3 \%$ respondent suffered from swelling of leg or face,
$18.2 \%$ respondents from anemia; $15.2 \%$ respondents suffered from burning micturation, $12.1 \%$ respondents from ante partum haemorrhage and convulsion. The following table is given below in detail: 


\begin{tabular}{|c|c|c|}
\hline \multicolumn{3}{|l|}{ Types of Complications } \\
\hline During Pregnancy $(n=33)$ & During Delivery $(\mathbf{n}=15)$ & Post-Delivery $(n=14)$ \\
\hline Excessive Vomiting (66.7\%) & Obstructed Labour (33.3\%) & $\begin{array}{l}\text { High Fever with Foul Smelling Discharge } \\
(85.7 \%)\end{array}$ \\
\hline Severe Headache $(66.7 \%)$ & Prolonged Labour (26.7\%) & Post-partum Hemorrhage (42.9\%) \\
\hline Blurring of Vision (66.7\%) & Eclampsia $(26.7 \%)$ & Post-partum Eclampsia (42.9\%) \\
\hline Swelling of Leg/Face (27.3\%) & Abnormal Position of Foetus (13.3\%) & \\
\hline Anaemia $(18.2 \%)$ & & \\
\hline Burning Micturition (15.2\%) & & \\
\hline $\mathrm{APH}(12.1 \%)$ & & \\
\hline Convulsion $(12.1 \%)$ & & \\
\hline
\end{tabular}

In table-10 shows delivery information among the respondents. Most of the patients deliver occurred in home, $78.6 \%$. The following table is given below in detail:

Table-10: Distribution of delivery information among the respondents $(n=112)$

\begin{tabular}{|l|l|l|l|}
\hline \multicolumn{2}{|l|}{ Delivery Information } & Frequency & Percentage (\%) \\
\hline Place of Delivery & Home & 88 & 78.6 \\
\cline { 2 - 4 } & Hospital & 24 & 21.4 \\
\hline Mode of Delivery & NVD & 106 & 94.6 \\
\cline { 2 - 4 } & LUCS & 06 & 5.4 \\
\hline \multirow{3}{*}{ Delivery } & TBA & 65 & 58.0 \\
\cline { 2 - 4 } & Nurse/Paramedics & 20 & 17.9 \\
\cline { 2 - 4 } & Doctor & 10 & 9.0 \\
\cline { 2 - 4 } & FWV & 08 & 7.1 \\
\cline { 2 - 4 } & Relatives & 08 & 7.1 \\
\cline { 2 - 4 } & CSBA & 01 & 0.9 \\
\hline
\end{tabular}

In table-11 shows treatment seeking behavior during complications among the respondents. Out of 33 respondent who faced complication during their pregnancy $23(70 \%)$ sought treatment and $10(30 \%)$ didn't take any treatment. Among them 12 (52.2\%) respondents seek treatment in government hospital and rest of them in private clinic. The following table is given below in detail:

Table-11: Distribution of treatment seeking behavior during complications among the respondents

\begin{tabular}{|l|l|l|l|l|}
\hline \multirow{2}{*}{ Treatment Seeking Behaviors } & \multicolumn{3}{l|}{ Complications } \\
\cline { 3 - 5 } & & $\begin{array}{l}\text { During } \\
\text { Pregnancy }\end{array}$ & $\begin{array}{l}\text { During } \\
\text { Delivery }\end{array}$ & Post-Delivery \\
\hline \multirow{3}{*}{ Sought Treatment } & Yes & $23(69.7)$ & $15(100.0)$ & $14(100.0)$ \\
\cline { 2 - 5 } & No & $10(30.3)$ & $00(0.0)$ & $00(0.0)$ \\
\hline \multirow{5}{*}{ Place of Seeking Treatment } & Govt. Hospital & $12(52.2)$ & $10(66.7)$ & $03(21.4)$ \\
\cline { 2 - 5 } & Private Clinic & $11(47.8)$ & $03(20.0)$ & $05(35.7)$ \\
\cline { 2 - 5 } & Satellite Clinic & $00(0.0)$ & $00(0.0)$ & $02(14.3)$ \\
\cline { 2 - 5 } & Pharmacy & $00(0.0)$ & $00(0.0)$ & $02(14.3)$ \\
\cline { 2 - 5 } & At Home & $00(0.0)$ & $02(13.3)$ & $02(14.3)$ \\
\hline Care/Treatment Provided by & Doctor & $19(82.6)$ & $12(80.0)$ & $08(57.1)$ \\
\cline { 2 - 5 } & Nurse/Paramedics & $04(17.4)$ & $01(6.7)$ & $04(28.6)$ \\
\cline { 2 - 5 } & TBA & $00(0.0)$ & $02(13.3)$ & $00(0.0)$ \\
\cline { 2 - 5 } & FWV & $00(0.0)$ & $00(0.0)$ & $02(14.3)$ \\
\hline \multirow{5}{*}{ Types of Treatment Received } & Tablets/Capsules & $19(82.6)$ & $01(6.7)$ & $09(64.3)$ \\
\cline { 2 - 5 } & Saline/Injections & $04(17.4)$ & $14(93.3)$ & $05(35.7)$ \\
\hline Barriers Faced While Seeking Treatment & No Barrier Faced & $15(65.3)$ & $08(53.3)$ & $13(92.9)$ \\
\cline { 2 - 5 } & Expenditure & $07(30.4)$ & $04(16.7)$ & $01(7.1)$ \\
\cline { 2 - 5 } & Delay in Starting Treatment & $01(4.3)$ & $03(20.0)$ & $00(0.0)$ \\
\hline
\end{tabular}

In table-12 shows association between ANC and complications among the respondents. Among 33 respondents, patients who faced complication during pregnancy, only $48.8 \%$ received ANC. The following table is given below in detail: 
Table-12: Association between ANC and complications among the respondents

\begin{tabular}{|l|l|l|l|l|l|}
\hline \multirow{2}{*}{ Complications } & ANC & \multirow{2}{*}{ Total } & \multirow{2}{*}{$\chi^{2}$ Test Significance } \\
\cline { 3 - 6 } & Received & Not Received & & \\
\cline { 3 - 5 } & $\mathrm{n}(\%)$ & $\mathrm{n}(\%)$ & $\mathrm{n}$ & \\
\hline \multirow{2}{*}{ Pregnancy Complication } & Present & $13(18.3)$ & $20(48.8)$ & 33 & \multirow{2}{*}{$\mathrm{P}=0.001^{\mathrm{HS}}$} \\
\cline { 2 - 5 } & Absent & $58(81.7)$ & $21(51.2)$ & 79 & \\
\hline \multirow{2}{*}{ Delivery Complication } & Present & $06(8.4)$ & $09(21.9)$ & 15 & $\mathrm{P}=0.083^{\mathrm{NS}}$ \\
\cline { 2 - 5 } & Absent & $65(91.6)$ & $32(78.1)$ & 97 & \\
\hline Post-Delivery Complication & Present & $07(9.9)$ & $07(17.1)$ & 14 & \multirow{2}{*}{$\mathrm{P}=0.415^{\mathrm{NS}}$} \\
\cline { 2 - 5 } & Absent & $64(90.1)$ & $34(82.9)$ & $\mathbf{9 8}$ & \\
\hline Total & 71 & 41 & 112 & \\
\hline
\end{tabular}

In table-13 shows health seeking behavior according to complications among the respondents. Out of 14 respondents $2.86 \%$ health seeking behaviorwere unhealthy. The following table is given below in detail:

Table-13: Distribution of health seeking behavior according to complications among the respondents

\begin{tabular}{|l|l|l|l|l|}
\hline \multirow{2}{*}{ Complications } & \multicolumn{4}{|l|}{ Health Seeking Behavior } \\
\cline { 2 - 5 } & \multicolumn{3}{|c|}{ Healthy Behavior } & \multicolumn{3}{|l|}{ Unhealthy Behavior } \\
\cline { 2 - 5 } & $\mathrm{n}$ & $\%$ & $\mathrm{n}$ & $\%$ \\
\hline $\begin{array}{l}\text { Pregnancy Complication } \\
(\mathrm{n}=33)\end{array}$ & 23 & 69.7 & 10 & 30.3 \\
\hline $\begin{array}{l}\text { Delivery Complication } \\
(\mathrm{n}=15)\end{array}$ & 13 & 86.7 & 02 & 13.3 \\
\hline Post-Delivery Complication $(\mathrm{n}=14)$ & 10 & 71.4 & 04 & 28.6 \\
\hline
\end{tabular}

\section{DISCUSSION}

In this study $63.4 \%$ respondents had received antenatal checkup from different health facilities. $<4$ times received $23.9 \%$ and 4 times taken $43.7 \%$ and $>4$ times $32.4 \%$. Promotion of antenatal checkup is essential for detection of high-risk pregnancy. Place of antenatal care were government hospital $47.8 \%$, FWC $26.8 \%$, private hospital $16.9 \%$, satellite clinic $8.5 \%$.

The necessity of antenatal checkup is to be promoted by motivation of other family members including husband. The provision of financial incentives in promoting and getting ANC, delivery care and postnatal care through the Demand Side Financing scheme of the Department for International Development UK has been found to be encouraging. The institutional or delivery under the care of skilled birth attendant has been found to increase from $18 \%$ national average to $27 \%$ in the DSF areas in Bangladesh [5]. From this finding government of Bangladesh is planning to expand the program in other areas.

In this study ANC receiving rate was relatively higher might be due to availability of health facilities in the study place because there is a community clinic, satellite clinic, and Family welfare center and also Upazilla Health complex nearby. The accessibility of ANC facility close proximity to the mother is essential. In future availability of functional community clinic thorough the country might change the scenario of ANC amongst the rural community.

Among the respondents $30 \%$ faced complications during their last pregnancy period and complications were excessive vomiting and severe headache with blurring vision $66.7 \%$, swelling of leg/face $27.3 \%$ severe anemia $18.2 \%$ burning micturation $15.2 \%$, Ante partum Haemorrhage (APH) and convulsion $12.1 \%$. Out of 33 respondent who were faced complication during their pregnancy $23(70 \%)$ sought treatment and $10(30 \%)$ were not taken any treatment. $12(52.2 \%)$ respondents seek treatment in govt. hospital and $11(47.8 \%)$ in private clinic. Treatment given by the doctor were $19(82.6 \%)$ and nurse/paramedic $04(17.4 \%) .82 .6 \%$ were treated by tablet/capsule and $17.4 \%$ were treated by saline/injections.

In another study showed that most common pattern of care seeking was bringing medicine and/or treatment to the home $(67.7 \%)[6]$. Women and their families tended to seek this type of treatment for postpartum/cramping pain $(90.9 \%)$, bleeding $(70.2 \%)$, symptoms of infection $(71.4 \%)$ and prolonged /obstructed labour (77.3\%). Almost half of the women reported taking tablets/capsules to address the complication $(44.5 \%)$, while few women reported receiving an injection to speed up labour $(2.1 \%)$. Few women reported that a provider was brought to the home to treat the complication $(19.9 \%)$.

In Uttar Pradesh, India they found seven complications during pregnancy period. Those were night blindness (14.5\%), blurred vision (28.5\%), convulsions (16.8\%), swelling $(24.7 \%)$, excessive fatigue $(45.2 \%)$, anaemia $(31.1 \%)$ and vaginal bleeding $(4.6 \%)$. About $90 \%$ were visited by health worker and few went to clinic [7]. 
In a study in Nigeriathey observed some of the serious pregnancy-related risks were differently perceived by Nigerian women. Many of the women would not perceive these risks as being too serious as they were regarded as normal and to be expected during pregnancy and they didn't seek any kind of health facility [8].

In this study $13.4 \%$ mother faced complication during their last delivery period and complication were obstructed labour 33.3\%, prolong labour $26.7 \%$ eclampsia $26.7 \%$, abnormal position of foetus $13.4 \%$. Among 15(13.4\%) respondents who have faced complications during their delivery period all sought treatment. $66.7 \%$ respondents seek treatment in govt. hospital and $20 \%$ in private clinic and $13.3 \%$ at home. $80 \%$ were treated by doctor, $13.3 \%$ by nurse/paramedics and $6.7 \%$ by TBA. During seeking treatment $53.3 \%$ did not face any problem, $26.7 \%$ face problem in expenditure and $20 \%$ delay of stating treatment.

One study results demonstrated a strong preference for private facilities for reasons that included availability of doctors, better equipment and facilities. They said that, women's perception of the quality of care available at the facility significantly influenced their choice [9]. Another study reported that in the northern Pakistan, the gender of health care providers, quality of service provided at the health facility and the associated financial cost were important factors in considering whom to consult [10].

Another study which was conducted in Pakistan said that, usage of public facilities was lower in rural areas due to restricted hours of operation, nonavailability of drugs, distant locations and lack of female providers [11].

Other report mentioned in their study that, women generally are looked after and follow decisions of the husbandin their community [12]. Similar patterns of care seeking in pregnancy have been shown in several studies $[13,14]$.

\section{Conclusion}

From our study we can conclude that, all the respondents who developed complications during delivery and after delivery sought health care. Among the respondents who did not receive antenatal care developed more complications during pregnancy period and delivery period which is statistically. Care seeking behavior is closely related with pregnancy complication. Timely and properly seeking treatment could help to reduce maternal mortality and morbidity and ultimately helps to reach MDG Goal.

\section{REFERENCE}

1. WHO/UNICEF/UNFPA. Maternal mortality in 2000: estimates developed by WHO, UNICEF, UNFPA.WHO/RHR01.9. Geneva, World Health Organization; 2004.

2. Report on Making Pregnancy and Childbirth Safer. European Commission/United Nations Population Fund Initiative for Reproductive Health in Asia in cooperation with the German Foundation for World Population, City. European Commission/United Nations Population Fund; 2000.

3. Nwakoby BN. Use of obstetric services in rural Nigeria. J Roy SocPromot Health.1994; 114(3):132-136.

4. Chakraborty N, Islam MA, Chowdhury RI, Bari W \&Akhter HH. Determinants of the use of maternal health services in rural Bangladesh. Health Promot Int.2003a; 18(4):327.

5. Faveau V. Matlab Maternity Care Program. [Review paper.] World Bank, Washington, DC.1991.

6. FaveauV, Stewart K, Khan SA\& Chakraborty J. Effect on mortality of community-based maternity careprogram in rural Bangladesh. The Lancet. 1991; 338:1183-1186.

7. Bhatia JC \& Cleland J. Determinants of maternal care in a region of South India. Health Transition Review.1995; 5:127-142.

8. Ronsmans C, Graham WJ. Maternal mortality: who, when, where, and why. Lancet. 2006;368(9542):1189-200.

9. University of British Columbia. Community Level Interventions for Pre-eclampsia (CLIP). In: ClinicalTrials.gov: National Library of Medicine (US). 2013 - [cited 29 Feb. 2016].

10. About

Sindh. http://www.sindh.gov.pk/aboutsindh.htm. Accessed 26 Dec. 2014.

11. Mumtaz Z, Salway SM. Gender, pregnancy and the uptake of antenatal care services in Pakistan. Sociol Health Illn. 2007;29(1):1-26.

12. Durr EN. Health-seeking behaviour of women reporting symptoms of reproductive tract infections. Pakistan Dev Rev. 2005;44(1):1-35.

13. Kruszewski P, Bieniaszewski L, Neubauer J, Krupa-Wojciechowska B. Headache in patients with mild to moderate hypertension is generally not associated with simultaneous blood pressure elevation. J Hypertens. 2000;18(4):437-44.

14. Sperling JD, Dahlke JD, Huber WJ, Sibai BM. The role of headache in the classification and management of hypertensive disorders in pregnancy. Obstet Gynecol. 2015;126(2):297-302. 